ARTICLE

\title{
Unprecedentedly high activity and selectivity for hydrogenation of nitroarenes with single atomic $\mathrm{Co}_{1}-\mathrm{N}_{3} \mathrm{P}_{1}$ sites
}

\author{
Hongqiang Jin ${ }^{1,2}$, Peipei $\mathrm{Li}^{1,2}$, Peixin Cui (iD) ${ }^{3}$, Jinan Shi ${ }^{4,5}$, Wu Zhou (iD ${ }^{4,5}$, Xiaohu Yu (iD ${ }^{6 凶}$, Weiguo Song ${ }^{1,2}$ \& \\ Changyan Cao id 1,2凶
}

Transition metal single atom catalysts ( $S A C s$ ) with $M_{1}-N_{x}$ coordination configuration have shown outstanding activity and selectivity for hydrogenation of nitroarenes. Modulating the atomic coordination structure has emerged as a promising strategy to further improve the catalytic performance. Herein, we report an atomic $\mathrm{Co}_{1} / \mathrm{NPC}$ catalyst with unsymmetrical single $\mathrm{Co}_{1}-\mathrm{N}_{3} \mathrm{P}_{1}$ sites that displays unprecedentedly high activity and chemoselectivity for hydrogenation of functionalized nitroarenes. Compared to the most popular $\mathrm{Co}_{1}-\mathrm{N}_{4}$ coordination, the electron density of $\mathrm{Co}$ atom in $\mathrm{Co}_{1}-\mathrm{N}_{3} \mathrm{P}_{1}$ is increased, which is more favorable for $\mathrm{H}_{2}$ dissociation as verified by kinetic isotope effect and density functional theory calculation results. In nitrobenzene hydrogenation reaction, the as-synthesized $\mathrm{Co}_{1}-\mathrm{N}_{3} \mathrm{P}_{1} \mathrm{SAC}$ exhibits a turnover frequency of $6560 \mathrm{~h}^{-1}$, which is 60 -fold higher than that of $\mathrm{Co}_{1}-\mathrm{N}_{4} \mathrm{SAC}$ and one order of magnitude higher than the state-of-the-art $\mathrm{M}_{1}-\mathrm{N}_{\mathrm{x}}-\mathrm{C}$ SACs in literatures. Furthermore, $\mathrm{Co}_{1}-\mathrm{N}_{3} \mathrm{P}_{1} \mathrm{SAC}$ shows superior selectivity ( $>99 \%$ ) toward many substituted nitroarenes with co-existence of other sensitive reducible groups. This work is an excellent example of relationship between catalytic performance and the coordination environment of SACs, and offers a potential practical catalyst for aromatic amine synthesis by hydrogenation of nitroarenes.

\footnotetext{
${ }^{1}$ Beijing National Laboratory for Molecular Sciences, CAS Research/Education Center for Excellence in Molecular Sciences, Laboratory of Molecular Nanostructures and Nanotechnology, Institute of Chemistry, Chinese Academy of Sciences, Beijing 100190, China. ${ }^{2}$ School of Chemical Sciences, University of Chinese Academy of Sciences, Beijing 100049, China. ${ }^{3}$ Key Laboratory of Soil Environment and Pollution Remediation, Institute of Soil Science, Chinese Academy of Sciences, Nanjing 210008, China. ${ }^{4}$ School of Physical Sciences, CAS Key Laboratory of Vacuum Physics, University of Chinese Academy of Sciences, Beijing 100049, China. ${ }^{5}$ CAS Center for Excellence in Topological Quantum Computation, University of Chinese Academy of Sciences, Beijing 100049, China. ${ }^{6}$ Institute of Theoretical and Computational Chemistry, Shaanxi Key Laboratory of Catalysis, School of Chemical \& Environment Sciences, Shaanxi University of Technology, Hanzhong 723000, China. ${ }^{凶}$ email: yuxiaohu@snut.edu.cn; cycao@iccas.ac.cn
} 
C hemoselective hydrogenation of nitroarenes is a key reaction in the fine chemical industry and has wide applications in the synthesis of pigments and pharmaceuticals ${ }^{1-4}$. Noble metal nanocatalysts (e.g., $\mathrm{Pt}, \mathrm{Au}$, and $\mathrm{Pd}$ ) are usually used for this reaction ${ }^{5-7}$. However, noble metal catalysts are costly and their high activities usually come with unsatisfactory selectivity against many substituted nitroarenes ${ }^{8-11}$. Since Beller et al. reported highly selective traditional metal catalysts based on $\mathrm{Co}_{3} \mathrm{O}_{4} @ \mathrm{~N} / \mathrm{C}$ and $\mathrm{Fe}_{3} \mathrm{O}_{4} @ \mathrm{~N} / \mathrm{C}$, it has sparked intensive research interest in this type of catalysts ${ }^{1,12}$. Among them, transition metal single-atom catalysts (SACs) with $\mathrm{M}_{1}-\mathrm{N}_{\mathrm{x}}-\mathrm{C}(\mathrm{M}=\mathrm{Fe}, \mathrm{Co}, \mathrm{Ni}$, $\mathrm{x}=2-6$ ) coordination configuration exhibited much better activities than their counterpart nanoparticles while maintaining high selectivity, owing to their maximum atom efficiency and particular electronic structure ${ }^{13-18}$. Recently, Wang et al. found that the electron density of $\mathrm{Ni}$ single atoms increased with the decrease of $\mathrm{Ni}-\mathrm{N}$ coordination numbers $(\mathrm{CN})$, and the capability of $\mathrm{Ni}$ single sites to dissociate $\mathrm{H}_{2}$ was greatly enhanced, leading to higher catalytic activity in chemoselective hydrogenation of functionalized nitroarenes ${ }^{19}$. This result suggests that the catalytic activity of $\mathrm{M}_{1}-\mathrm{N}_{\mathrm{x}}-\mathrm{C}$ can also be enhanced by adjusting the coordination structure of transition metal SACs.

In most SACs, the central metal atoms were stabilized by coordination bonds with $\mathrm{N}, \mathrm{S}, \mathrm{O}$, etc. atoms within support matrix ${ }^{20-29}$. The electronic and geometric structures of central metal atoms can be adjusted by tailoring the coordination environment, which would change the absorption energy of reactants on metal atoms and thus influence the catalytic process ${ }^{20,23,28,30}$. For SACs with $\mathrm{M}_{1}-\mathrm{N}_{\mathrm{x}}-\mathrm{C}$ sites, the symmetric electronic distribution may limit the activation of reactants, thereby leading to hampered catalytic kinetics and performances ${ }^{20,31}$. Recent studies have found that introducing heteroatom $\mathrm{P}$ for an unsymmetrical $\mathrm{N} / \mathrm{P}$ mixed-coordination can further modulate the electronic properties of center metal atoms. The unsymmetrical geometric structure can evoke the distortion of electronic density and alter the d-band center $20,23,28,31,32$. For example, Yuan et al. prepared an N/P dual-coordinated Fe single-atom catalyst, which was more favorable for the adsorption of oxygen intermediates for ORR in fuel cell ${ }^{23}$. Li et al. reported that a $\mathrm{Fe}_{1}-\mathrm{N}_{3} \mathrm{P}_{1}$ single-atom nanozyme exhibited peroxidase-like catalytic activity, and the high activity was ascribed to the less positive charge on $\mathrm{Fe}$ atoms as $\mathrm{P}$ atoms are electron donors ${ }^{32}$. Thus, we anticipated that constructing the unsymmetrical N/P dual-coordinated transition metal SACs would improve the catalytic performance for the hydrogenation of nitroarenes.

In this work, we report an N/P dual-coordinated Co SAC (denoted as $\mathrm{Co}_{1} / \mathrm{NPC}$ ) with $\mathrm{Co}_{1}-\mathrm{N}_{3} \mathrm{P}_{1}$ coordination structure and investigate its catalytic performance for chemoselective hydrogenation of nitroarenes. The single atomic feature and coordination structure of the $\mathrm{Co}_{1}-\mathrm{N}_{3} \mathrm{P}_{1}$ site are characterized through aberration-corrected high angle annular dark-field scanning transmission electron microscopy (AC HAADF-STEM), atomicresolution electron energy-loss spectroscopy (EELS), X-ray photoelectron spectroscopy (XPS), and X-ray absorption spectrum (XAS). In nitrobenzene hydrogenation reaction, the $\mathrm{Co}_{1}-\mathrm{N}_{3} \mathrm{P}_{1}$ SAC exhibits a turnover frequency of $6560 \mathrm{~h}^{-1}$, which is 60 times higher than that of $\mathrm{Co}_{1}-\mathrm{N}_{4}$ SAC and 10 times higher than the state-of-the-art $\mathrm{M}_{1}-\mathrm{N}_{\mathrm{x}}-\mathrm{C}$ SACs in literatures. Furthermore, $\mathrm{Co}_{1}$ $\mathrm{N}_{3} \mathrm{P}_{1}$ SAC shows superior selectivity (>99\%) toward many substituted nitroarenes with the co-existence of other sensitive reducible groups. The unprecedentedly high activity of $\mathrm{Co}_{1}-\mathrm{N}_{3} \mathrm{P}_{1}$ SAC can be ascribed to the upshift d-band center of Co single atoms, which is more favorable for $\mathrm{H}_{2}$ dissociation as verified by the kinetic isotope effect and density functional theory calculation results. This is an excellent example of such an unsymmetrical N/ $\mathrm{P}$ dual-coordinated structure of metal SACs in hydrogenation.

\section{Results}

Structural characterization. Supplementary Fig. 1 illustrates the synthesis procedures for preparing N/P dual-coordinated Co SAC (denoted as $\mathrm{Co}_{1} / \mathrm{NPC}$ ) via a two-step process. First, tannic acid, (2-Aminoethyl)phosphonic acid (AePA), and cobalt ion precursors were co-adsorbed on the surface of graphitic carbon nitride $\left(\mathrm{g}-\mathrm{C}_{3} \mathrm{~N}_{4}\right)$ nanosheets; then the resultant powder was subjected to pyrolysis under flowing $\mathrm{Ar}$ gas at $900{ }^{\circ} \mathrm{C}$ to obtain $\mathrm{Co}_{1} / \mathrm{NPC}$, where the AePA was absent and the introduced-P species served as the donors for anchoring Co atoms (Supplementary Fig. 2). For comparison, N-coordinated Co SAC (denoted as $\mathrm{Co}_{1} / \mathrm{NC}$ ) was also prepared via the same procedure without the addition of AePA. As exhibited in Raman spectra, the carbon matrices in both $\mathrm{Co}_{1} / \mathrm{NPC}$ and $\mathrm{Co}_{1} / \mathrm{NC}$ were disordered with a large number of defects (Supplementary Fig. 3). Only two broad peaks at $\sim 24.3^{\circ}$ and $42.6^{\circ}$ could be observed from their X-ray diffraction (XRD) patterns (Supplementary Fig. 4), corresponding to (002) and (101) planes of carbon, suggesting highly dispersed states of Co species in both of two samples. Further increasing the pyrolysis temperature of $\mathrm{Co}_{1} / \mathrm{NPC}$ to $1000^{\circ} \mathrm{C}$ led to the formation of $\mathrm{Co}_{2} \mathrm{P}$ nanoparticles (Supplementary Figs. 4, 5). Scanning electron microscopy (SEM) and transmission electron microscopy (TEM) images show that both catalysts retain a two-dimensional layered structure and no obvious nanoparticles are observed (Supplementary Figs. 6, 7). Energy-dispersive spectroscopy (EDS) mappings reveal Co elements are distributed uniformly over the entire samples (Supplementary Figs. 8, 9). Additionally, Co single-atom feature in $\mathrm{Co}_{1} / \mathrm{NPC}$ and $\mathrm{Co}_{1} / \mathrm{NC}$ is directly observed by AC HAADF-STEM, as reflected by the highly dispersed bright dots due to the heavy Z-contrast (Fig. 1a and Supplementary Fig. 10). The Co loading in $\mathrm{Co}_{1} / \mathrm{NPC}$ was $\sim 0.45 \mathrm{wt} \%$ as determined by the inductively coupled plasma mass spectroscopy (ICP-MS) analysis (Supplementary Table 1). The porosity features of $\mathrm{Co}_{1} / \mathrm{NC}$ and $\mathrm{Co}_{1} / \mathrm{NPC}$ were investigated using nitrogen physisorption measurements. Both catalysts displayed characteristics of IV-type $\mathrm{N}_{2}$ adsorption-desorption isotherms, suggesting the existence of mesopores, which would be beneficial for the exposure of active sites and mass transportation (Supplementary Fig. 11). The calculated BET-specific surface area of $\mathrm{Co}_{1} / \mathrm{NC}$ and $\mathrm{Co}_{1} / \mathrm{NPC}$ were 512 and $471 \mathrm{~m}^{2} \mathrm{~g}^{-1}$, respectively.

XPS was then applied to reveal the chemical structures of both Co SACs. In $\mathrm{N} 1 s$ spectra, besides pyridinic $\mathrm{N}$, pyrrolic $\mathrm{N}$, graphitic $\mathrm{N}$, and oxidized $\mathrm{N}$ species, a peak at $399.1 \mathrm{eV}$ corresponding to Co- $\mathrm{N}$ can be distinguished ${ }^{33}$, indicating the existence of $\mathrm{N}$ coordination environment with Co single atoms in both catalysts (Fig. 1b and Supplementary Fig. 12). Note that from $\mathrm{P} 2 p$ spectra in Fig. 1c, an obvious peak at $\sim 129.3 \mathrm{eV}$ corresponding to $\mathrm{Co}-\mathrm{P}$ bond was presented in $\mathrm{Co}_{1} / \mathrm{NPC}^{23,31}$, which can also be observed in the comparison $\mathrm{Co}_{2} \mathrm{P}$ NPs/C (Supplementary Fig. 13); while it is absent in $\mathrm{Co}_{1} / \mathrm{NC}$ sample. These results suggest that the atomically dispersed Co atoms possess N/P dual-coordinated configuration in $\mathrm{Co}_{1} / \mathrm{NPC}$, while only $\mathrm{N}$-coordinated configuration in $\mathrm{Co}_{1} / \mathrm{NC}$.

To further determine the coordination environment of $\mathrm{Co}$ single atoms, X-ray absorption fine structure (XAFS) measurements were conducted. Figure $1 \mathrm{~d}$ shows the Co K-edge X-ray absorption near-edge structure (XANES) curves of $\mathrm{Co}_{1} / \mathrm{NC}$ and $\mathrm{Co}_{1} / \mathrm{NPC}$, with $\mathrm{Co}$ foil, $\mathrm{CoO}$, and cobalt phthalocyanine $(\mathrm{CoPc})$ as reference samples. It can be seen that the absorption threshold positions for $\mathrm{Co}_{1} / \mathrm{NC}$ and $\mathrm{Co}_{1} / \mathrm{NPC}$ are located between Co foil and $\mathrm{CoO}$, suggesting that the valence states of $\mathrm{Co}$ species are between 0 and +2 in both two catalysts. Moreover, the Co K-edge position and white line of $\mathrm{Co}_{1} / \mathrm{NPC}$ are lower than that of $\mathrm{Co}_{1} /$ $\mathrm{NC}$ (inset of Fig. 1d), which indicates that Co atoms in $\mathrm{Co}_{1} / \mathrm{NPC}$ possess more negative charges than $\mathrm{Co}_{1} / \mathrm{NC}$. Such difference could be attributed to the less electron transfer from Co to $\mathrm{P}$ 

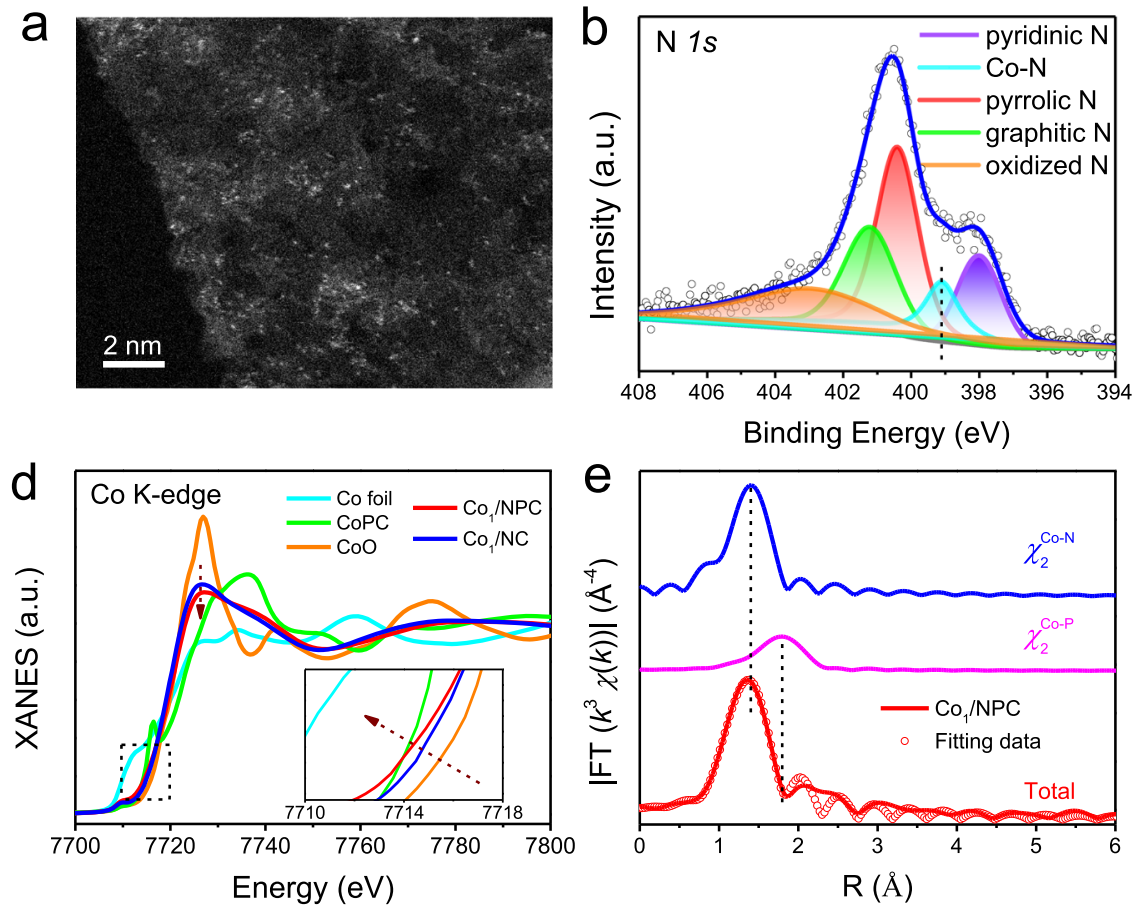
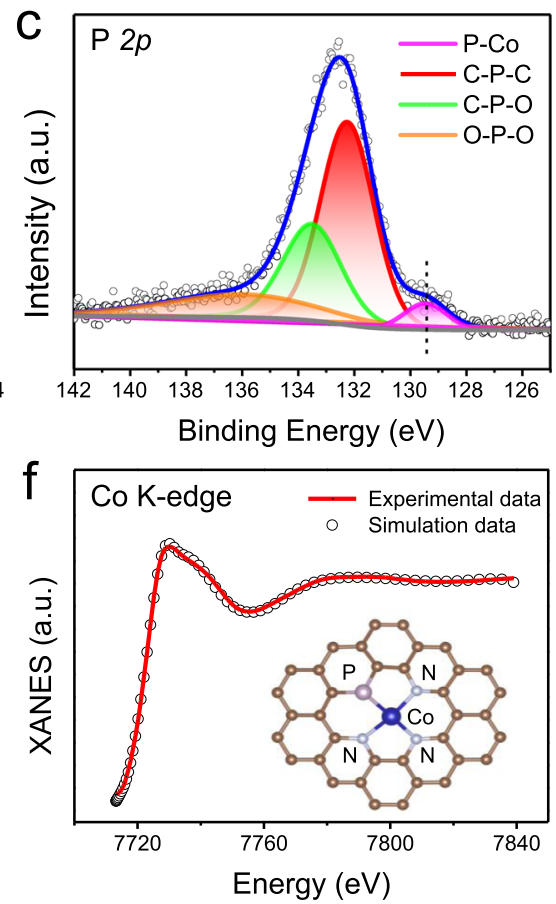

Fig. 1 Structural Characterizations of $\mathbf{C o}_{1} / \mathbf{N P C}$. a AC HAADF-STEM image of $\mathrm{Co}_{1} / \mathrm{NPC}$. b N $1 \mathrm{~s}$ and $\mathbf{c} \mathrm{P} 2 p$ XPS spectra of Co 1 NPC. d Co K-edge XANES

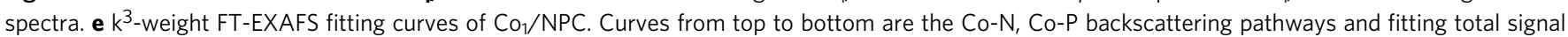
(red circle) superimposed on the experimental signal (red line). $\mathbf{f}$ The experimental XANES curve in comparison with the calculated XANES data of Co, $\mathrm{N}_{3} \mathrm{P}_{1}$ site in $\mathrm{Co}_{1} / \mathrm{NPC}$ sample. Inset: the schematic atomic structure of $\mathrm{Co}_{1} / \mathrm{NPC}$ derived from the EXAFS results.

because of the weaker electronegativity of $\mathrm{P}$ than $\mathrm{N}$ atoms ${ }^{20}$. The Fourier-transformed $k^{3}$-weighted EXAFS (FT-EXAFS) spectra demonstrated that both $\mathrm{Co}_{1} / \mathrm{NC}$ and $\mathrm{Co}_{1} / \mathrm{NPC}$ only exhibited a prominent peak at $1.38 \AA$ (without phase shift), no Co-Co peaks at $2.17 \AA$ or larger bond distances were detected, confirming atomically dispersed $\mathrm{Co}$ species in $\mathrm{Co}_{1} / \mathrm{NC}$ and $\mathrm{Co}_{1} / \mathrm{NPC}$ (Supplementary Figs. 14, 15). The coordination configuration of Co moieties was further surveyed using quantitative least-squares EXAFS curve-fitting. The EXAFS spectrum of $\mathrm{Co}_{1} / \mathrm{NPC}$ was investigated by utilizing $\mathrm{Co}-\mathrm{N}$ and $\mathrm{Co}-\mathrm{P}$ backscattering pathways. The best-fitting analysis displays that the main peak at $1.38 \AA$ could be satisfactorily interpreted as Co-N first-shell coordination with $\mathrm{CN}=3.2 \pm 0.1$ and the shoulder peak at $1.77 \AA$ originated from Co-P contribution with $\mathrm{CN}=0.9 \pm 0.1$ (Fig. $1 \mathrm{e}$ and Supplementary Table 2), suggesting the possible $\mathrm{Co}_{1}-\mathrm{N}_{3} \mathrm{P}_{1}$ configuration in $\mathrm{Co}_{1} / \mathrm{NPC}$. For comparison, fitting of $\mathrm{Co}_{1} / \mathrm{NC}$ resulted in an average of about four $\mathrm{N}$ atoms with a distance of $1.37 \AA$ (Supplementary Fig. 14 and Supplementary Table 2). In order to better confirm the proposed configurations, the theoretical XANES spectrum were simulated based on the $\mathrm{Co}_{1}$ $\mathrm{N}_{3} \mathrm{P}_{1}$ model as well as $\mathrm{Co}_{1}-\mathrm{N}_{4}$, which presented a good agreement with the experimental data, indicating the rationality of the two structures (Fig. 1f and Supplementary Fig. 16).

Besides, we performed atomic-resolution electron energy-loss spectroscopy (EELS) analysis at a relatively low beam current to minimize electron-beam perturbations to provide strong evidence of $\mathrm{Co}_{1}-\mathrm{N}_{3} \mathrm{P}_{1}$ structure (Fig. 2a, b). The extracted Co L-edge EELS spectrum from Fig. 2d presents a clear Co signal (Fig. 2g), providing direct evidence for the presence of atomically dispersed Co species. More importantly, the existence of $\mathrm{N}, \mathrm{P}$ dualcoordination vicinal to $\mathrm{Co}$ site is revealed by identifying the surrounding heteroatoms. From the N, P, and overlap maps (Fig. 2e, f, c), three $\mathrm{N}$ atoms (green) and one $\mathrm{P}$ atom (red) exist around the Co site. Atomic-scale N K-edge and P L-edge EELS spectra collected at the corresponding positions from Fig. 2e, f are further demonstrated by the $\mathrm{N}$ and $\mathrm{P}$ signals (Fig. 2h, i). This forcefully confirms the $\mathrm{Co}_{1}-\mathrm{N}_{3} \mathrm{P}_{1}$ configuration in $\mathrm{Co}_{1} / \mathrm{NPC}$ sample. Moreover, the formation energy of the $\mathrm{Co}_{1}-\mathrm{N}_{3} \mathrm{P}_{1}$ structure in the $\mathrm{Co}_{1} / \mathrm{NPC}$ sample was estimated to be about $-0.864 \mathrm{eV}$ by DFT calculation, indicating the high stability of the proposed configuration (Supplementary Fig. 17). These results revealed that the Co single sites in $\mathrm{Co}_{1} / \mathrm{NPC}$ were stabilized with $\mathrm{N} / \mathrm{P}$ dual-coordinated structure, forming an unsymmetrical $\mathrm{Co}_{1}$ $\mathrm{N}_{3} \mathrm{P}_{1}$ geometric configuration (as depicted in Fig. 1f), which is different from the $\mathrm{Co}$ site in $\mathrm{Co}_{1} / \mathrm{NC}$ with traditional in-plane $\mathrm{Co}_{1}-\mathrm{N}_{4}$ configuration.

Catalytic performance. To evaluate the catalytic performances of the as-prepared Co SACs for the hydrogenation of nitroarenes, nitrobenzene is first chosen as a probe molecule. The reaction kinetics with $\mathrm{Co}_{1} / \mathrm{NC}$ and $\mathrm{Co}_{1} / \mathrm{NPC}$ were obtained at $110^{\circ} \mathrm{C}$ with $3 \mathrm{MPa} \mathrm{H}_{2}$ in a Teflon-lined stainless steel autoclave. As shown in Fig. 3a, $\mathrm{Co}_{1} / \mathrm{NPC}$ exhibits significantly higher activity than that of $\mathrm{Co}_{1} / \mathrm{NC}$. Nitrobenzene was completely converted with $>99 \%$ amine selectivity in $210 \mathrm{~min}$ with $\mathrm{Co}_{1} / \mathrm{NPC}$, while less than $20 \%$ conversion was observed with $\mathrm{Co}_{1} / \mathrm{NC}$ under the same reaction condition. In addition, no conversion was observed with $\mathrm{NC}$ and NPC supports, suggesting that atomic Co site was active species in both $\mathrm{Co}_{1} / \mathrm{NC}$ and $\mathrm{Co}_{1} / \mathrm{NPC}$ catalysts (Supplementary Fig. 18). The reaction rate $(\mathrm{k})$ for hydrogenation of nitrobenzene over $\mathrm{Co}_{1} /$ NPC could reach as high as $35.9 \mathrm{~mol} \mathrm{~mol}^{-1} \mathrm{~min}^{-1}$, which is ten times higher than that with $\mathrm{Co}_{1} / \mathrm{NC}\left(3.1 \mathrm{~mol} \mathrm{~mol}^{-1} \mathrm{~min}^{-1}\right)$.

The turnover frequency value (TOF) (based on the substrate conversion at about $20 \%$ ) of $\mathrm{Co}_{1} / \mathrm{NPC}$ is calculated to be $6560 \mathrm{~h}^{-1}$, which is over 60 times higher than that with $\mathrm{Co}_{1} / \mathrm{NC}\left(108 \mathrm{~h}^{-1}\right)$ (Fig. 3b). Besides nitrobenzene, $\mathrm{Co}_{1} / \mathrm{NPC}$ also exhibited superior high activity and excellent selectivity $(>99.7 \%)$ for hydrogenation of 3 -nitrostyrene with TOF of $4499 \mathrm{~h}^{-1}$. The impressive activity of $\mathrm{Co}_{1} /$ NPC is ten times higher than the state-of-the-art $\mathrm{M}_{1}-\mathrm{N}_{\mathrm{x}}-\mathrm{C}$ SACs in 

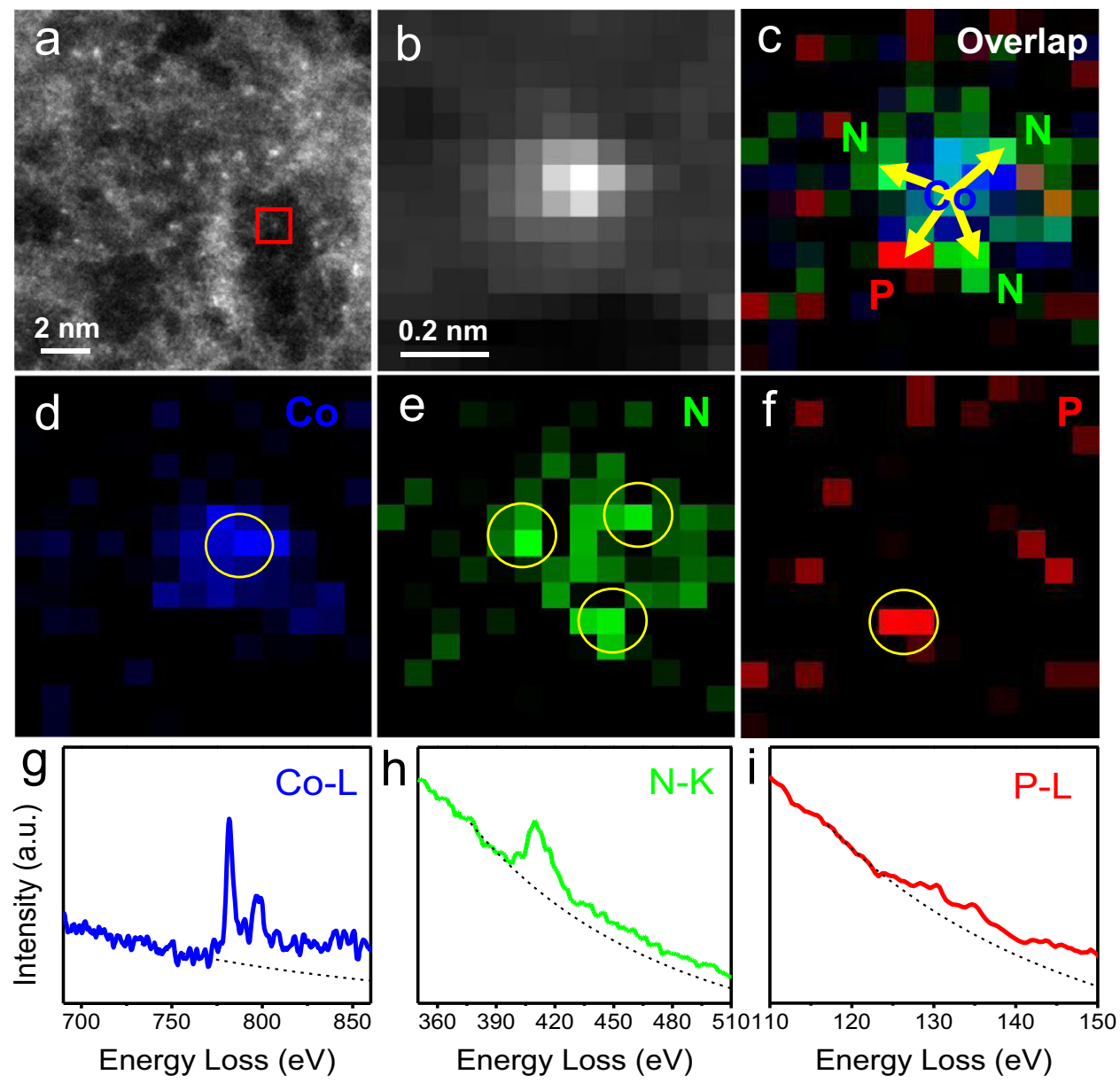

Fig. 2 Atomic-resolution EELS analysis of $\mathbf{C o}_{1} /$ NPC sample. a AC HAADF-STEM image of $\mathrm{Co}_{1} / \mathrm{NPC}$ sample at a relatively low beam current. $\mathbf{b}$ HAADF image acquired simultaneously with atomic-resolution EELS mapping of $\mathrm{Co}_{1} / N P C$ at the red square area in (a). c The overlap map of $\mathrm{P}, \mathrm{N}$, and Co elements. d-f Elemental maps of Co, N, P, respectively. $\mathbf{g}$-i The EELS spectra extracted at the yellow circled position from (d-f), respectively.

literature (Fig. $3 c$ and Supplementary Table 3) ${ }^{34-43}$. Such excellent catalytic performance of $\mathrm{Co}_{1} / \mathrm{NPC}$ sample inspired us to carry out the reaction under milder conditions (e.g., $40^{\circ} \mathrm{C}, 1$ bar $\mathrm{H}_{2}$ ). A high nitrobenzene conversion of $97.2 \%$ was achieved within $5 \mathrm{~h}$ (Supplementary Fig. 19). To further compare the catalytic performance between $\mathrm{Co}_{1} / \mathrm{NC}$ and $\mathrm{Co}_{1} / \mathrm{NPC}$, the apparent activation energies of these two catalysts were measured (Supplementary Fig. 20 and Supplementary Table 4). As shown in Fig. 3d, the calculated activation energy of $\mathrm{Co}_{1} / \mathrm{NPC}$ catalyst is about $21.8 \mathrm{~kJ} \mathrm{~mol}^{-1}$, which is much lower than that of $\mathrm{Co}_{1} / \mathrm{NC}\left(51.3 \mathrm{~kJ} \mathrm{~mol}^{-1}\right)$.

In order to clarify the intrinsic higher activity of $\mathrm{Co}_{1}-\mathrm{N}_{3} \mathrm{P}_{1}$, the electronic properties of the central metal sites over $\mathrm{Co}_{1} / \mathrm{NC}$ and $\mathrm{Co}_{1} /$ NPC are examined by electron-density isosurface and partial density of states from DFT calculations. Different charge distributions of the two models are observed (Fig. 3e). Compare to the $\mathrm{Co}_{1}-\mathrm{N}_{4}$ configuration, the symmetric electron structure is broken by introducing heteroatom $\mathrm{P}$ in $\mathrm{Co}_{1}-\mathrm{N}_{3} \mathrm{P}_{1}$. The Bader charge of the $\mathrm{Co}_{1}-\mathrm{N}_{3} \mathrm{P}_{1}$ site is estimated to be $+0.81 e$, while the $\mathrm{Co}_{1}-\mathrm{N}_{4}$ site is $+0.97 e$, indicating the Co atom in the $\mathrm{Co}_{1}-\mathrm{N}_{3} \mathrm{P}_{1}$ site carries more charge since the $\mathrm{P}$ element in the $\mathrm{Co}_{1} / \mathrm{NPC}$ transfers $2.308 e$ to support, which is consistent with the XAFS results. Moreover, the Co d-band center of $\mathrm{Co}_{1} / \mathrm{NPC}$ is up-shifted, much closer to the Fermi level (Fig. 3f). As a result, the antibonding state of Co atoms and adsorbed $\mathrm{H}_{2}$ species are more occupied, then such change enhances the capabilities of $\mathrm{H}_{2}$ dissociation ${ }^{6,44}$. Thus, $\mathrm{Co}_{1} / \mathrm{NPC}$ catalyst with $\mathrm{Co}_{1}-\mathrm{N}_{3} \mathrm{P}_{1}$ configuration exhibits much higher activity than that of $\mathrm{Co}_{1} / \mathrm{NC}$ with $\mathrm{Co}_{1}-\mathrm{N}_{4}$ configuration.
Catalytic hydrogenation mechanism. Such a large activity difference between $\mathrm{Co}_{1} / \mathrm{NC}$ and $\mathrm{Co}_{1} / \mathrm{NPC}$ implies that the hydrogenation activity is closely correlated with local coordination structure, which influences the electronic structure of Co single atoms. In order to elucidate the reaction mechanisms on both catalysts, we carried out a kinetic isotope effect (KIE) study to examine the $\mathrm{H}_{2}$ dissociation step. Using $\mathrm{D}_{2}$ for nitrobenzene hydrogenation, the reaction rate was slowed down by a factor of 3.25 for $\mathrm{Co}_{1} / \mathrm{NC}$ (Fig. 4a). For comparison, a larger $\mathrm{KIE}\left(\mathrm{k}_{\mathrm{H}} /\right.$ $\mathrm{k}_{\mathrm{D}}=5.54$ ) was observed on $\mathrm{Co}_{1} / \mathrm{NPC}$ catalyst (Fig. $4 \mathrm{~b}$ ). These results suggest that $\mathrm{H}_{2}$ dissociation undergoes heterolytic cleavage on both $\mathrm{Co}_{1} / \mathrm{NC}$ and $\mathrm{Co}_{1} / \mathrm{NPC}^{45-47}$.

It is generally accepted that heterolytic cleavage of $\mathrm{H}_{2}$ on metal single atoms occurs to form metal- $\mathrm{H}^{\delta-}$ and heteroatom- $\mathrm{H}^{\delta+45,48}$. Therefore, DFT calculations were further performed to understand the $\mathrm{H}_{2}$ heterolytic cleavage on $\mathrm{Co}_{1} / \mathrm{NC}$ and $\mathrm{Co}_{1} / \mathrm{NPC}$, respectively. As shown in Supplementary Fig. 21, the $\mathrm{H}_{2}$ molecule is adsorbed on the $\mathrm{Co}$ atom of $\mathrm{Co}_{1} / \mathrm{NPC}$ with adsorption energy of $-0.08 \mathrm{eV}$, and the bond length of $\mathrm{H}_{2}$ is $0.814 \AA$, which is much longer than free molecular $\mathrm{H}_{2}(0.752 \AA)$ in the gas phase. While $\mathrm{H}_{2}$ molecule is adsorbed on $\mathrm{Co}$ atom of $\mathrm{Co}_{1} / \mathrm{NC}$ with adsorption energy of $0.033 \mathrm{eV}$, and the bond length of $\mathrm{H}_{2}$ is $0.783 \AA$. The much longer $\mathrm{H}-\mathrm{H}$ bond length of adsorbed molecule $\mathrm{H}_{2}$ indicates that $\mathrm{Co}_{1} / \mathrm{NPC}$ has a higher activation ability for $\mathrm{H}_{2}$ dissociation than $\mathrm{Co}_{1} / \mathrm{NC}$. Subsequently, one of the $\mathrm{H}$ atoms moves to a nearby heteroatom $(\mathrm{N}$ and $\mathrm{P})$ to yield heteroatom- $\mathrm{H}^{\delta+}$, leaving another $\mathrm{H}$ atom on $\mathrm{Co}$ atom as $\mathrm{Co}-\mathrm{H}^{\delta}$. Direct dissociation of $\mathrm{H}_{2}$ 

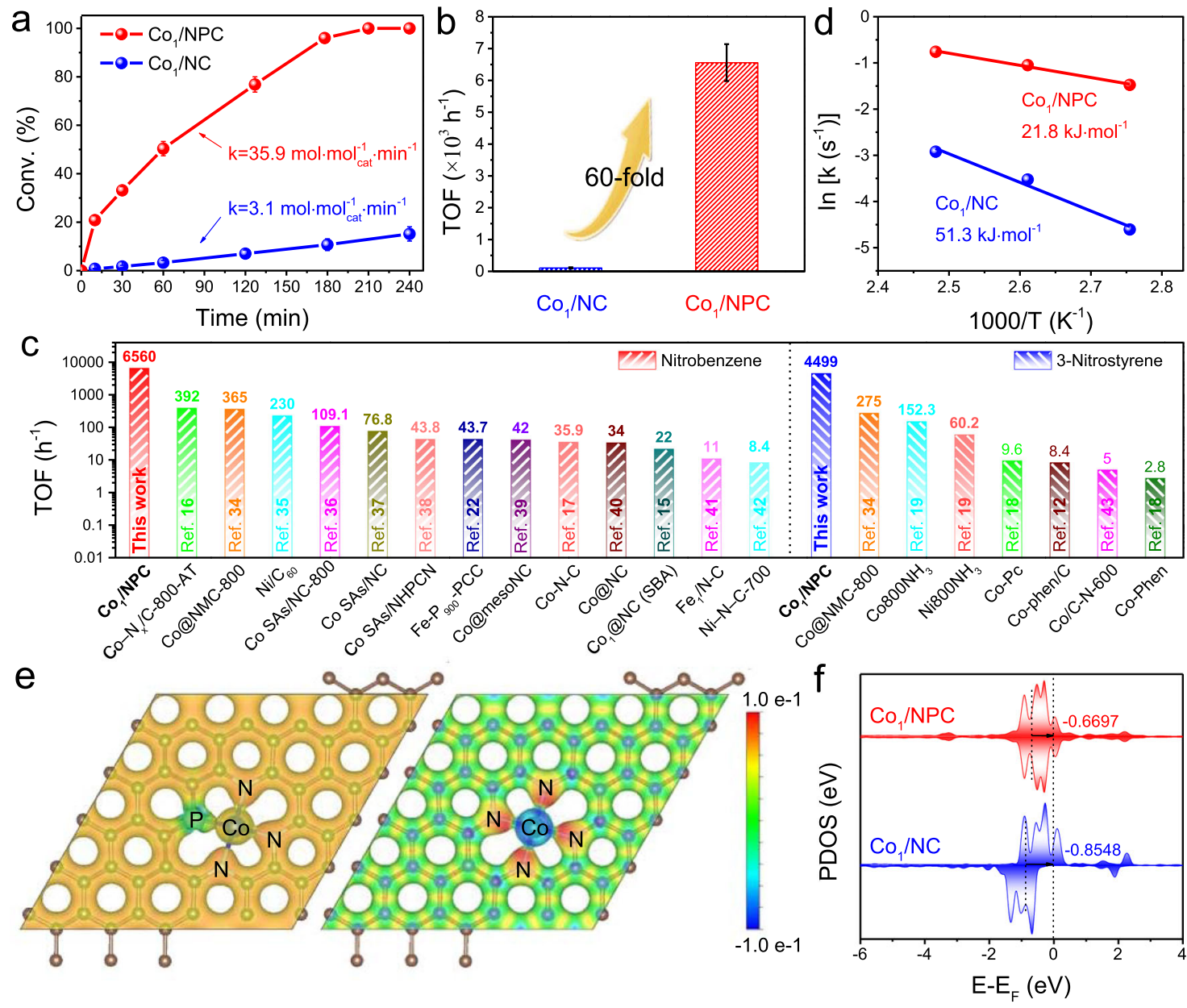

Fig. 3 Catalytic performances and kinetic process studies. a Time course of nitrobenzene conversions over $\mathrm{Co}_{1} / \mathrm{NPC}$ and $\mathrm{Co}_{1} / \mathrm{NC}$ samples. The standard deviations were derived from three independent trials. Reaction conditions: $5 \mathrm{mg}$ catalyst, $2 \mathrm{mmol}$ nitrobenzene, $40 \mathrm{~mL} \mathrm{EtOH} / \mathrm{H}_{2} \mathrm{O}(\mathrm{v}: \mathrm{v}=4: 1), 110{ }^{\circ} \mathrm{C}$, $3 \mathrm{MPa} \mathrm{H}$. b TOF of $\mathrm{Co}_{1} / \mathrm{NPC}$ and $\mathrm{Co}_{1} / \mathrm{NC}$ for the nitrobenzene hydrogenation. The TOF values were calculated at about $20 \%$ conversion. $\mathbf{c}$ The TOF values comparison of recently reported transition metal catalysts. $\mathbf{d}$ The experimental Arrhenius plots of $\mathrm{Co}_{1} / \mathrm{NPC}$ and $\mathrm{Co}_{1} / \mathrm{NC}$. e Electron-density isosurface of $\mathrm{Co}$ atoms in two models. Blue color indicates positive charges and red color indicates negative charge. f Partial density of states (PDOS) of Co atoms in $\mathrm{Co}_{1} / \mathrm{NPC}$ and $\mathrm{Co}_{1} / \mathrm{NC}$, the zero-energy corresponds to the Fermi level, and the d-band centers are inserted with the short dot.

on both $\mathrm{Co}_{1} / \mathrm{NPC}$ and $\mathrm{Co}_{1} / \mathrm{NC}$ in the absence of water, the transition state is almost the same $(\sim 1.21 \mathrm{eV})$, the only difference is that the dissociation of $\mathrm{H}_{2}$ on $\mathrm{Co}_{1} / \mathrm{NPC}$ is exothermic by $0.20 \mathrm{eV}$, while on $\mathrm{Co}_{1} / \mathrm{NPC}$ is endothermic by $1.11 \mathrm{eV}$, suggesting such dissociation manner on $\mathrm{Co}_{1}-\mathrm{N}_{4}$ site is thermodynamically unfavorable (Supplementary Fig. 22). The above difference in the DFT calculations confirms that $\mathrm{Co}_{1}-\mathrm{N}_{3} \mathrm{P}_{1}$ exhibits much higher catalytic activity for heterolytic cleavage of $\mathrm{H}_{2}$.

Ding et al. ${ }^{18}$. reported that the protic solvents play a dominant role in the case of Co-N-C-catalyzed hydrogenation of nitroarenes, where the solvent-mediated $\mathrm{H}$-shuttling mechanism is crucial in the reaction pathway. Compared to the intrinsic hydrogen transfer, the protic solvent-mediated one usually possesses a lower activation barrier, leading to an enhancement of hydrogenation activity in the presence of water or alcohol ${ }^{49}$. Indeed, both $\mathrm{Co}_{1} / \mathrm{NC}$ and $\mathrm{Co}_{1} / \mathrm{NPC}$ show the best activities under ethanol/water solvent and significantly decreased activities in an aprotic solvent such as toluene, acetonitrile, THF, and n-hexane (Supplementary Fig. 23). Further DFT calculations suggest that the activation energy barriers with water-mediated $\mathrm{H}$-shuttling mechanism for the heterolytic cleavage of $\mathrm{H}_{2}$ are lower by about 0.16 and $0.01 \mathrm{eV}$ than that through direct dissociation on $\mathrm{Co}_{1}$ $\mathrm{N}_{3} \mathrm{P}_{1}$ and $\mathrm{Co}_{1}-\mathrm{N}_{4}$ sites, respectively (Fig. $4 \mathrm{c}, \mathrm{d}$ ). Both kinetic and thermodynamic results suggest that the dissociative activation of $\mathrm{H}_{2}$ with help of $\mathrm{H}_{2} \mathrm{O}$ is more favorable to $\mathrm{Co}_{1} / \mathrm{NPC}$ catalyst.

According to the previous reports, the hydrogenation reduction of nitrobenzene to aniline follows the Haber mechanism ${ }^{7}$, namely, $\mathrm{PhNO}_{2}{ }^{*} \rightarrow \mathrm{PhNOOH}^{*} \rightarrow \mathrm{PhNO}^{*} \rightarrow \mathrm{PhNOH}^{*} \rightarrow \mathrm{PhNHOH}^{*} \rightarrow$ $\mathrm{PhNH}^{*} \rightarrow \mathrm{PhNH}_{2}{ }^{*}$. Based on the above results and reported mechanism in literature, the reaction pathway for hydrogenation of nitrobenzene over $\mathrm{Co}_{1}-\mathrm{N}_{3} \mathrm{P}_{1}$ catalyst is further proposed by virtue of DFT calculations, as shown in Fig. 5 and Supplementary Fig. 24. One $\mathrm{H}_{2}$ molecule first goes through heterolytic cleavage with the assistance of the $\mathrm{H}_{2} \mathrm{O}$-mediated $\mathrm{H}$-shuttling mechanism to form $\mathrm{Co}-\mathrm{H}^{\delta-}$ and $\mathrm{P}-\mathrm{H}^{\delta+}$ at $\mathrm{Co}_{1}-\mathrm{N}_{3} \mathrm{P}_{1}$ sites, which can serve as the initial state for the hydrogenation process (Fig. 5a and Supplementary Fig. 25). Then, the target nitrobenzene molecule was adsorbed on the $\mathrm{Co}_{1}-\mathrm{N}_{3} \mathrm{P}_{1}$ site with a free energy of $-0.78 \mathrm{eV}$ (Fig. 5b, I). Subsequently, the activated $\mathrm{H}$ atom on Co- $\mathrm{H}^{\delta-}$ and the $\mathrm{O}$ atom of $\mathrm{PhNO}_{2}$ are combined to produce $\mathrm{PhNOOH}$ intermediate, which is later reduced to $\mathrm{PhNO}$ intermediate by the $\mathrm{H}$ atom transfer from $\mathrm{P}_{-} \mathrm{H}^{\delta+}$ (II). Notably, the PhNO intermediate can be detected during the reaction process (Supplementary Fig. 26). After that, another $\mathrm{H}_{2}$ molecule is dissociated to form an activated $\mathrm{H}$ atom, which attacks the oxygen atom of $\mathrm{PhNO}$ and reduces it to $\mathrm{PhNHOH}$ (III, IV). It is worth 

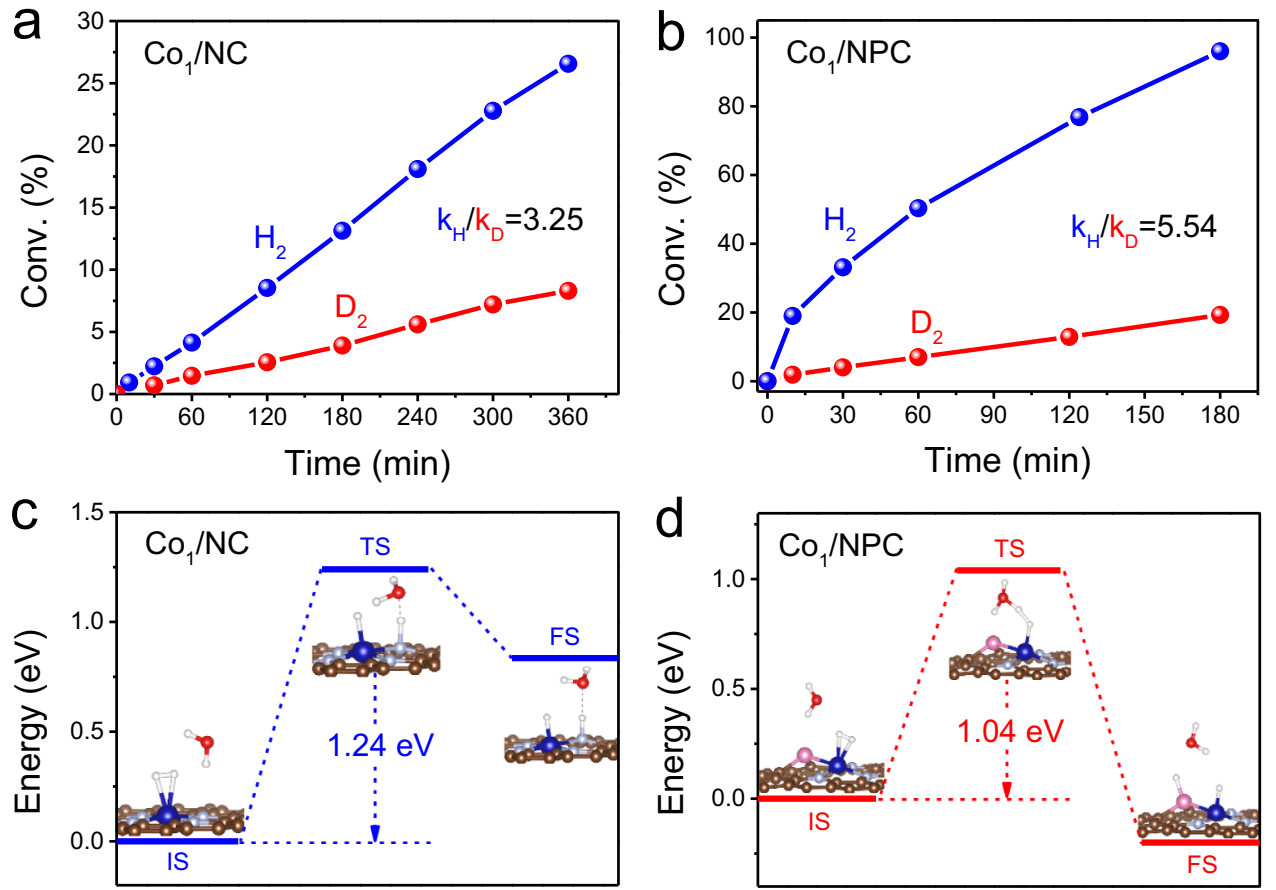

Reaction coordinate

Reaction coordinate

Fig. 4 Catalytic mechanism for the hydrogenation of nitrobenzene. Primary isotope effect observed on a $\mathrm{Co}_{1} / \mathrm{NC}$ and $\mathbf{b} \mathrm{Co}_{1} / \mathrm{NPC}$. Reaction conditions: $5 \mathrm{mg}$ catalyst, $2 \mathrm{mmol}$ nitrobenzene, $40 \mathrm{~mL}$ EtOH$/ \mathrm{H}_{2} \mathrm{O}\left(\mathrm{D}_{2} \mathrm{O}\right)(\mathrm{v}: \mathrm{v}=4: 1), 110{ }^{\circ} \mathrm{C}, 3 \mathrm{MPa} \mathrm{H}_{2}\left(\mathrm{D}_{2}\right)$. Energies profiles for $\mathrm{H}_{2}$ dissociation pathways of c $\mathrm{Co}_{1} /$ $\mathrm{NC}$ and $\mathbf{d} \mathrm{Co}_{1} / \mathrm{NPC}$ samples. IS initial state, TS transition state, FS final state.

noting that the adsorption energies of intermediates $\mathrm{PhNO}$ and $\mathrm{PhNHOH}$ on the $\mathrm{Co}_{1}-\mathrm{N}_{3} \mathrm{P}_{1}$ site are more favorable than $\mathrm{Ph}-\mathrm{NO}_{2}$, ensuring the reaction progress of the targeted substrate (Supplementary Fig. 27). In the next step, the third $\mathrm{H}_{2}$ molecule participates in and the formed $\mathrm{H}$ atom interacts with $\mathrm{PhNHOH}$ to generate the final $\mathrm{PhNH}_{2}$ product (V, FS). It can be seen the whole process is highly endothermic, confirming the possibility of the proposed reaction path.

Substrate exploration and catalytic stability. A broad scope of substituted nitroarenes was tested to examine the chemoselectivity in nitroarene hydrogenation (Fig. 6). $\mathrm{Co}_{1} / \mathrm{NPC}$ shows impressive chemoselectivity toward the substituted nitroarenes in the presence of other sensitive reducible groups, such as alkenyl (99.7\%, 2b), halogen (>98.9\%, 2c-f), ketones (>99\%, 2g, h), nitrile groups $(>99 \%, 2 \mathrm{i})$, etc. Notably, $\mathrm{Co}_{1} / \mathrm{NPC}$ also exhibits high activity and selectivity toward heterocyclic nitro-compounds $(>99 \%, 2 n-q)$. The superior high selectivity to corresponding anilines is ascribed to the unique character of metal SACs, where there is only one single metal atom for adsorption and activation of substrates.

Furthermore, $\mathrm{Co}_{1} / \mathrm{NPC}$ exhibited tolerable stability. As shown in Supplementary Fig. 28, a slight decrease of activity is observed after five cycles with $\mathrm{Co}_{1} / \mathrm{NPC}$, which can be ascribed to the loss of some catalysts and active Co species during the recycling experiments (Supplementary Table 1). The AC HAADF-STEM image and Co K-edge EXAFS spectrum of spent $\mathrm{Co}_{1} / \mathrm{NPC}$ indicate that the atomically dispersed Co species is well preserved after five cycles (Supplementary Fig. 29). All these results demonstrate that the $\mathrm{Co}_{1} / \mathrm{NPC}$ catalyst with unsymmetrical $\mathrm{Co}_{1}-\mathrm{N}_{3} \mathrm{P}_{1}$ configuration possesses unprecedented high activity, high selectivity, and good stability to a wide scope of substrates for hydrogenation of nitroarenes.

\section{Discussion}

In summary, we produced an atomically dispersed $\mathrm{Co}_{1} / \mathrm{NPC}$ catalyst with an unsymmetrically $\mathrm{Co}_{1}-\mathrm{N}_{3} \mathrm{P}_{1}$ coordination structure. Due to the increased electron density and upshift d-band center of $\mathrm{Co}$ atoms in $\mathrm{Co}_{1}-\mathrm{N}_{3} \mathrm{P}_{1}, \mathrm{H}_{2}$ dissociation was proved to be more favorable, resulting in much enhanced catalytic activity. In nitrobenzene hydrogenation reaction, the as-prepared $\mathrm{Co}_{1}-\mathrm{N}_{3} \mathrm{P}_{1}$ SAC exhibited a 60 -fold higher TOF value $\left(6560 \mathrm{~h}^{-1}\right)$ than that of $\mathrm{Co}_{1}-\mathrm{N}_{4} \mathrm{SAC}$ and more than tenfold higher than the state-of-theart $\mathrm{M}_{1}-\mathrm{N}_{\mathrm{x}}-\mathrm{C}$ SACs in literature. In addition, $\mathrm{Co}_{1}-\mathrm{N}_{3} \mathrm{P}_{1} \mathrm{SAC}$ also displayed superior selectivity (>99\%) towards the substituted nitroarenes with the co-existence of other sensitive reducible groups. This work provides new insight into rationally modulating the coordination structure of central metal atoms for boosting the catalytic performance of SACs in heterogeneous catalysis.

\section{Methods}

Synthesis of $\mathrm{Co}_{1} / \mathbf{N P C}$ and $\mathrm{Co}_{1} / \mathbf{N C}$. In a typical procedure, $\mathrm{Co}\left(\mathrm{NO}_{3}\right)_{2} \cdot 6 \mathrm{H}_{2} \mathrm{O}$ $(6.5 \mathrm{mg})$, tannic acid (TA, $500 \mathrm{mg}$ ), and (2-Aminoethyl) phosphonic acid (AePA, $126 \mathrm{mg}$ ) were dissolved into $30 \mathrm{~mL}$ DI water at $100^{\circ} \mathrm{C}$ (marked as solution A). g- $\mathrm{C}_{3} \mathrm{~N}_{4}$ nanosheets $(1 \mathrm{~g})$ were dispersed well in $100 \mathrm{~mL}$ DI water with ultrasound (marked as solution B). Then, solution A was added dropwise into solution B with a strong stirring at $100^{\circ} \mathrm{C}$ until the mixed system was forced to yield a slurry. Subsequently, the obtained powder after freeze-dried was pyrolyzed at $900^{\circ} \mathrm{C}$ for $2 \mathrm{~h}$ under $\mathrm{Ar}$ atmosphere. Finally, the as-prepared material was directly used without further treatment, denoted as $\mathrm{Co}_{1} / \mathrm{NPC}$.

The synthesis process for $\mathrm{Co}_{1} / \mathrm{NC}$ is the same as that of $\mathrm{Co}_{1} / \mathrm{NPC}$ except without the addition AePA.

Characterizations. The powder X-ray diffraction (XRD) patterns were recorded on a Rigaku D/max-2500n diffractometer with $\mathrm{Cu} \mathrm{Ka}$ radiation $(\lambda=1.5418 \AA)$ at $40 \mathrm{kV}$ and $200 \mathrm{~mA}$. The morphologies and microstructures of the samples were measured on the transmission electron microscopy (TEM) (JEM-2100F, JEOL, Japan) and the scanning electron microscopy (SEM) (HITACHI S-4800, Japan). Element mapping was characterized on TEM equipped with Oxford detection. $\mathrm{X}$-ray photoelectron spectroscopy (XPS) measurements were performed on a VG 

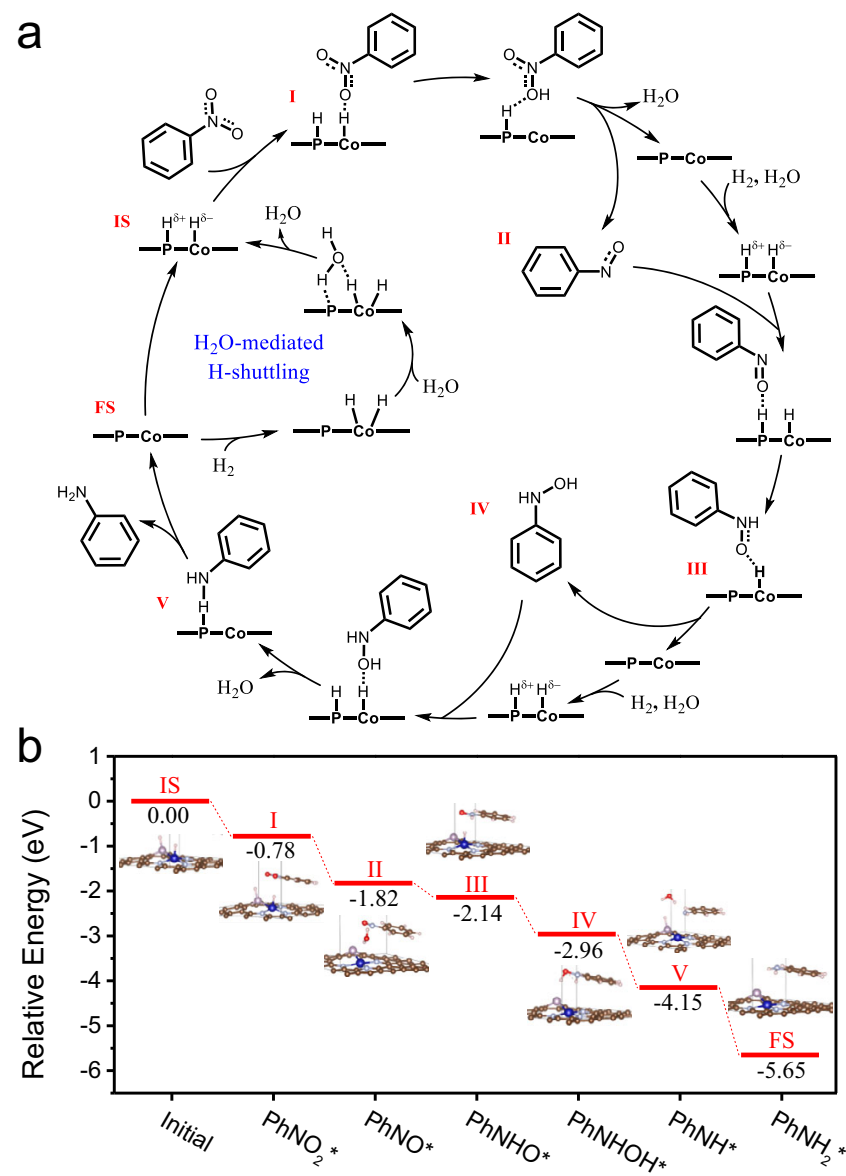

Fig. 5 Reaction mechanism of the nitrobenzene reduction. a The proposed reaction pathway for the hydrogenation of nitrobenzene to aniline at Co-P interface site. $\mathbf{b}$ Energy profile of hydrogenation of nitrobenzene over $\mathrm{Co}_{1}$ $\mathrm{N}_{3} \mathrm{P}_{1}$ site

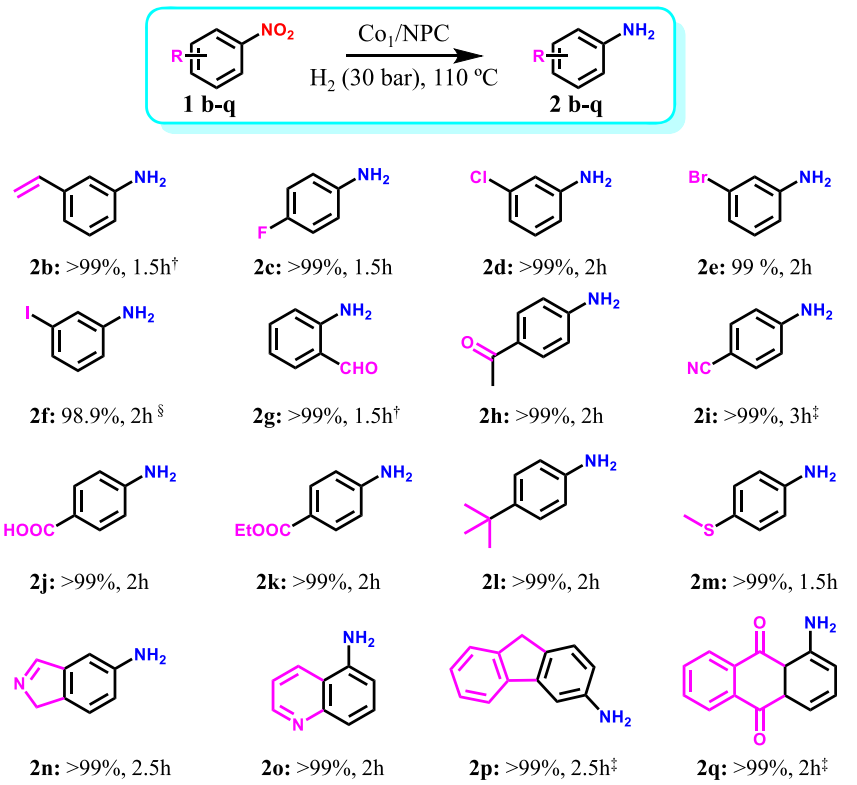

Fig. 6 Substrate scope of hydrogenation over the $\mathrm{Co}_{1} / \mathrm{NPC}$ catalyst.

Reaction conditions: $1 \mathrm{mmol}$ nitroarenes; $10 \mathrm{~mL} \mathrm{EtOH} ; 5 \mathrm{mg}$ catalyst; $110^{\circ} \mathrm{C}$; $3 \mathrm{MPa} \mathrm{H}$. ${ }^{\dagger} \mathrm{EtOH} / \mathrm{H}_{2} \mathrm{O}, \mathrm{v}-\mathrm{v}=4: 1,10 \mathrm{~mL} ;{ }^{\varsigma} \mathrm{H}_{2}, 2 \mathrm{MPa}$; temperature, $120^{\circ} \mathrm{C}$. In all cases, complete conversions of nitroarenes were observed.
Scientific ESCALab220i-XL electron spectrometer using $300 \mathrm{~W}$ Al ka radiation. Inductively coupled plasma atomic emission spectroscopy (ICP-AES) was conducted on a Shimadzu ICPE-9000 to confirm the loading content of metal on the catalysts. The AC HAADF-STEM images were carried out in a JEOL ARM300F at $300 \mathrm{kV}$, equipped with a probe spherical aberration corrector.

Brunauer-Emmett-Teller (BET) surface areas were measured by $\mathrm{N}_{2}$ adsorptiondesorption isotherms at $77 \mathrm{~K}$ with a Micromeritics ASAP 2460 instrument. The HAADF imaging and EELS mapping were both performed using a Nikon HERMES-100 aberration-corrected scanning transmission electron microscope under $60 \mathrm{kV}$ accelerating voltage with a $\sim 22 \mathrm{pA}$ probe. The probe convergence semi-angle, HAADF collection semi-angle, and EELS collection semi-angle is $32 \mathrm{mrad}, 75-210 \mathrm{mrad}$, and $0-75 \mathrm{mrad}$, respectively.

XAS measurements and analysis. The cobalt K-edges XAFS spectra of the standards and samples were collected at the beamline 1W1B of the Beijing Synchrotron Radiation Facility (BSRF). The typical energy of the storage ring was $2.5 \mathrm{GeV}$ and the electron current was $\sim 250 \mathrm{~mA}$ in the top-up mode. The white light was monochromatized by a Si (111) double-crystal monochromator and calibrated with a Co foil (K-edge at $7709 \mathrm{eV})$. Samples were pressed into thin slices and positioned at $45^{\circ}$ to the incident beam in the sample holder. The XAFS spectra were recorded in fluorescence mode with a Lytle detector oriented at $90^{\circ}$ to the incoming beam.

The XAFS data were analyzed using the software packages Demeter ${ }^{50}$. The spectra were normalized using Athena firstly, and then shell fittings were performed with Artemis. The $\chi(\mathrm{k})$ function was Fourier-transformed (FT) using $k^{3}$ weighting, and all fittings were done in R-space. The coordination parameters of samples were obtained by fitting the experimental peaks with theoretical amplitude. The quantitative curve-fittings were conducted with a Fourier transform k-space range of 2.7-11.8 $\AA^{-1}$. The backscattering amplitude $F(\mathrm{k})$ and phase shift $\Phi(\mathrm{k})$ were calculated by the FEFF7.0 code. While the curve-fitting, all the amplitude reduction factor $\mathrm{S}_{0}^{2}$ was set to the best-fit value of 0.87 determined from fitting the data of cobalt foil by fixing coordination numbers as the known crystallographic value. In order to fit the curves in the R-range of 1.0-2.0 $\AA$, we considered Co- $\mathrm{N}$ and Co-P paths as the central-peripheral. For each path, the structural parameters, like coordination number $(\mathrm{CN})$, interatomic distance $(\mathrm{R})$, Debye-Waller factors $\left(\sigma^{2}\right)$, and inner potential correction $\left(\Delta \mathrm{E}_{0}\right)$ were opened to be varied.

Catalytic performance evaluation. For the liquid phase hydrogenation of nitrobenzene, substrates $(2 \mathrm{mmol})$, catalyst $(5 \mathrm{mg})$, and solvent $\left(\mathrm{EtOH} / \mathrm{H}_{2} \mathrm{O}, \mathrm{v}-\mathrm{v}=4: 1\right.$, $40 \mathrm{~mL}$ ) were added into a $100 \mathrm{~mL}$ high-pressure autoclave. Then the autoclave was flushed three times with $\mathrm{H}_{2}$ and charged to certain pressure $\left(3 \mathrm{MPa} \mathrm{H}_{2}\right)$. The reaction was performed at the desired temperature. The product was collected at the reserved time and immediately analyzed using gas chromatography in combination with mass spectrometry (Shimadzu GCMS-QP2010S). The TOF values were determined within the substrate conversion below $20 \%$, and the calculation of TOF was based on the total Co amount in catalysts. To evaluate the reusability of catalyst, the samples from the last reaction were separated by centrifugation, washing with ethyl acetate to remove the substrate, and drying under the vacuum. For the kinetic isotope effect test, $\mathrm{D}_{2}$ and $\mathrm{D}_{2} \mathrm{O}$ are used instead of $\mathrm{H}_{2}$ and $\mathrm{H}_{2} \mathrm{O}$.

DFT calculations. All the spin-polarized first-principles calculations have used the code VASP ${ }^{51-53}$. Valence electrons of $\mathrm{O}(2 s, 2 p), \mathrm{N}(2 s, 2 p), \mathrm{H}(1 s), \mathrm{C}(2 s, 2 p), \mathrm{P}(3 s$, $3 p)$, and $\operatorname{Co}(3 d, 4 s)$ were treated on a basis of plane waves explicitly ${ }^{54}$, while the core electrons were described with the projector-augmented wave method ${ }^{55}$. Spinpolarized calculations were carried out at the level of the generalized gradient approximation (GGA) adopting the Perdew, Burke, and Ernzerhof (PBE) exchange-correlation functional ${ }^{56}$. A kinetic energy cutoff of $400 \mathrm{eV}$ was used for all calculations. The truncation criteria for the electronic and ionic loops were $10^{-5} \mathrm{eV}$ and $10^{-2} \mathrm{eV} / \AA$, respectively. Long-range dispersion was included according to the $\mathrm{D}_{3}$ method introduced by Grimme ${ }^{54}$. The vacuum layer was set to $20 \AA$ to avoid interaction from adjacent cells. All the transition states were determined by using the climbing image nudged elastic band (CINEB) method ${ }^{57,58}$ and transition states were characterized via frequency analysis to ensure a single imaginary frequency in the desired reaction direction. The pure graphene is modeled by a $(7 \times 7)$ supercell with 49 carbon atoms, and the Co- $\mathrm{N}_{\mathrm{x}} \mathrm{P}_{\mathrm{y}}$-Gr model is modeled by one cobalt atom adsorption at vacancy site which is composed by getting rid of two carbon atoms and the $\mathrm{N}$ and $\mathrm{P}$ atoms substitute for four carbon atoms around cobalt atom, respectively. Monkhorst-Pack $(5 \times 5 \times 1) \Gamma$-centered grid sampling for the Brillouin zone was used for geometry optimization, and dipole corrections were included in the z-direction for each model surface. To study the stability of Co binding on graphene with $\mathrm{N}, \mathrm{P}$ dual-coordination, the formation energy, and adsorption energy were defined as follows:

$$
\begin{gathered}
\mathrm{E}_{\text {for }}=\mathrm{E}\left(\mathrm{Co}-\mathrm{N}_{\mathrm{x}} \mathrm{P}_{\mathrm{y}}-\mathrm{Gr}\right)-\mathrm{E}\left(\mathrm{N}_{\mathrm{x}} \mathrm{P}_{\mathrm{y}}\right)-\mathrm{E}(\mathrm{Co}-\text { bulk }) \\
\mathrm{E}_{\mathrm{ads}}=\mathrm{E}\left(\mathrm{Co}-\mathrm{N}_{\mathrm{x}} \mathrm{P}_{\mathrm{y}}-\mathrm{Gr}\right)-\mathrm{E}\left(\mathrm{N}_{\mathrm{x}} \mathrm{P}_{\mathrm{y}}\right)-\mathrm{E}(\mathrm{Co})
\end{gathered}
$$

In the equations, $\mathrm{E}\left(\mathrm{Co}-\mathrm{N}_{\mathrm{x}} \mathrm{P}_{\mathrm{y}}-\mathrm{Gr}\right)$ is the total energy of adsorbed systems, $\mathrm{E}\left(\mathrm{N}_{\mathrm{x}} \mathrm{P}_{\mathrm{y}}\right)$ is the energy of graphene with doped $\mathrm{N}$ and $\mathrm{P}, \mathrm{E}$ (Co-bulk) is the energy of one atom in the most stable Co crystal, and $\mathrm{E}(\mathrm{Co})$ is the energy of cobalt in the gas phase. 


\section{Data availability}

The data supporting the findings of this study are available within the article and its Supplementary Information. Source data are provided with this paper. Additional data are available from the corresponding authors on reasonable request.

Received: 23 August 2021; Accepted: 3 January 2022;

Published online: 07 February 2022

\section{References}

1. Jagadeesh, R. V. et al. Nanoscale $\mathrm{Fe}_{2} \mathrm{O}_{3}$-based catalysts for selective hydrogenation of nitroarenes to anilines. Science 342, 1073-1076 (2013).

2. Zhang, L. L., Zhou, M. X., Wang, A. Q. \& Zhang, T. Selective hydrogenation over supported metal catalysts: from nanoparticles to single atoms. Chem. Rev. 120, 683-733 (2020)

3. Lang, R. et al. Single-atom catalysts based on the metal-oxide interaction. Chem. Rev. 120, 11986-12043 (2020).

4. Yan, H. et al. Atomic engineering of high-density isolated Co atoms on graphene with proximal-atom controlled reaction selectivity. Nat. Commun. 9, 3197 (2018).

5. Wei, $\mathrm{H}$. et al. $\mathrm{FeO}_{\mathrm{x}}$-supported platinum single-atom and pseudo-single-atom catalysts for chemoselective hydrogenation of functionalized nitroarenes. Nat. Commun. 5, 6634 (2014)

6. Ye, T.-N. et al. Stable single platinum atoms trapped in sub-nanometer cavities in $12 \mathrm{CaO} \cdot 7 \mathrm{Al}_{2} \mathrm{O}_{3}$ for chemoselective hydrogenation of nitroarenes. Nat. Commun. 11, 1020 (2020).

7. Zhang, S. et al. High catalytic activity and chemoselectivity of sub-nanometric $\mathrm{Pd}$ clusters on porous nanorods of $\mathrm{CeO}_{2}$ for hydrogenation of nitroarenes. $J$. Am. Chem. Soc. 138, 2629-2637 (2016).

8. Boronat, M. et al. A molecular mechanism for the chemoselective hydrogenation of substituted nitroaromatics with nanoparticles of gold on $\mathrm{TiO}_{2}$ catalysts: a cooperative effect between gold and the support. J. Am. Chem. Soc. 129, 16230-16237 (2007).

9. Serna, P. \& Corma, A. Transforming nano metal nonselective particulates into chemoselective catalysts for hydrogenation of substituted nitrobenzenes. ACS Catal. 5, 7114-7121 (2015)

10. Yang, X.-F. et al. Single-atom catalysts: a new frontier in heterogeneous catalysis. Acc. Chem. Res. 46, 1740-1748 (2013).

11. $\mathrm{Fu}, \mathrm{T}$. et al. Acid-resistant catalysis without use of noble metals: carbon nitride with underlying nickel. ACS Catal. 4, 2536-2543 (2014).

12. Westerhaus, F. A. et al. Heterogenized cobalt oxide catalysts for nitroarene reduction by pyrolysis of molecularly defined complexes. Nat. Chem. 5, 537-543 (2013).

13. Wang, Y. et al. Chemoselective hydrogenation of nitroaromatics at the nanoscale iron(III)-OH-platinum interface. Angew. Chem. Int. Ed. 59 $12736-12740$ (2020)

14. Li, H. et al. Cobalt single atoms anchored on $\mathrm{N}$-doped ultrathin carbon nanosheets for selective transfer hydrogenation of nitroarenes. Sci. China Mater. 62, 1306-1314 (2019)

15. Zhang, L. et al. Atomically dispersed Co catalyst for efficient hydrodeoxygenation of lignin-derived species and hydrogenation of nitroaromatics. ACS Catal. 10, 8672-8682 (2020).

16. Zhou, P. et al. High performance of a cobalt-nitrogen complex for the reduction and reductive coupling of nitro compounds into amines and their derivatives. Sci. Adv. 3, NO. e1601945 (2017).

17. Liu, W. et al. Single-atom dispersed Co-N-C catalyst: structure identification and performance for hydrogenative coupling of nitroarenes. Chem. Sci. 7 5758-5764 (2016).

18. $\mathrm{Li}, \mathrm{M}$. et al. Origin of the activity of Co-N-C catalysts for chemoselective hydrogenation of nitroarenes. ACS Catal. 11, 3026-3039 (2021).

19. Zhou, D. et al. Tuning the coordination environment of single-atom catalyst $\mathrm{M}-\mathrm{N}-\mathrm{C}$ towards selective hydrogenation of functionalized nitroarenes. Nano Res. 11, 1-9 (2021).

20. Wan, J. et al. In situ phosphatizing of triphenylphosphine encapsulated within metal-organic frameworks to design atomic $\mathrm{Co}_{1}-\mathrm{P}_{1} \mathrm{~N}_{3}$ interfacial structure for promoting catalytic performance. J. Am. Chem. Soc. 142, 8431-8439 (2020).

21. Wei, X. et al. Cross-linked polyphosphazene hollow nanosphere-derived N/Pdoped porous carbon with single nonprecious metal atoms for the oxygen reduction reaction. Angew. Chem. Int. Ed. 59, 14639-14646 (2020).

22. Long, X. et al. Graphitic phosphorus coordinated single Fe atoms for hydrogenative transformations. Nat. Commun. 11, 4074 (2020).

23. Yuan, $K$. et al. Boosting oxygen reduction of single iron active sites via geometric and electronic engineering: nitrogen and phosphorus dual coordination. J. Am. Chem. Soc. 142, 2404-2412 (2020).

24. Ren, Y. et al. Unraveling the coordination structure-performance relationship in $\mathrm{Pt}_{1} / \mathrm{Fe}_{2} \mathrm{O}_{3}$ single-atom catalyst. Nat. Commun. 10, 4500 (2019).
25. Liu, J. et al. Direct observation of metal oxide nanoparticles being transformed into metal single atoms with oxygen-coordinated structure and high-loadings. Angew. Chem. Int. Ed. 60, 15248-15253 (2021).

26. Wang, L. et al. A sulfur-tethering synthesis strategy toward high-loading atomically dispersed noble metal catalysts. Sci. Adv. 5, eaax6322 (2019).

27. Zhang, J. et al. Tuning the coordination environment in single-atom catalysts to achieve highly efficient oxygen reduction reactions. J. Am. Chem. Soc. 141 20118-20126 (2019)

28. Shang, $\mathrm{H}$. et al. Engineering unsymmetrically coordinated $\mathrm{Cu}-\mathrm{S}_{1} \mathrm{~N}_{3}$ single atom sites with enhanced oxygen reduction activity. Nat. Commun. 11, 3049 (2020).

29. Hai, X. et al. Engineering local and global structures of single Co atoms for a superior oxygen reduction reaction. ACS Catal. 10, 5862-5870 (2020).

30. Chen, C. et al. Zero-valent palladium single-atoms catalysts confined in black phosphorus for efficient semi-hydrogenation. Adv. Mater. 33, 2008471 (2021)

31. Chen, Y. et al. Atomic-level modulation of electronic density at cobalt singleatom sites derived from metal-organic frameworks: enhanced oxygen reduction performance. Angew. Chem. Int. Ed. 60, 3212-3221 (2021).

32. Ji, S. et al. Matching the kinetics of natural enzymes with a single-atom iron nanozyme. Nat. Catal. 4, 407-417 (2021).

33. Zhang, Y., Jiao, L., Yang, W., Xie, C. \& Jiang, H.-L. Rational fabrication of lowcoordinate single-atom Ni electrocatalysts by MOFs for highly selective $\mathrm{CO}_{2}$ reduction. Angew. Chem. Int. Ed. 60, 7607-7611 (2021).

34. Zhang, F. et al. In situ mosaic strategy generated Co-based N-doped mesoporous carbon for highly selective hydrogenation of nitroaromatics. $J$. Catal. 348, 212-222 (2017).

35. Qu, Y., Yang, H., Wang, S., Chen, T. \& Wang, G. Hydrogenation of nitrobenzene to aniline catalyzed by C-60-stabilized Ni. Catal. Commun. 97, 83-87 (2017)

36. He, J. et al. Strategic defect engineering of metal-organic frameworks for optimizing the fabrication of single-atom catalysts. Adv. Funct. Mater. 31 2103597 (2021)

37. Wang, H. et al. Highly efficient hydrogenation of nitroarenes by N-doped carbon-supported cobalt single-atom catalyst in ethanol/water mixed solvent. ACS Appl. Mater. Interfaces 12, 34021-34031 (2020).

38. Cai, Q. et al. Boosted catalytic hydrogenation performance using isolated Co sites anchored on nitrogen-incorporated hollow porous carbon. J. Phys. Chem. C. 125, 5088-5098 (2021)

39. Sun, X. et al. Single cobalt sites in mesoporous N-doped carbon matrix for selective catalytic hydrogenation of nitroarenes. J. Catal. 357, 20-28 (2018).

40. Sun, X. et al. Metal-organic framework mediated cobalt/nitrogen-doped carbon hybrids as efficient and chemoselective catalysts for the hydrogenation of nitroarenes. ChemCatChem 9, 1854-1862 (2017).

41. Tian, S. et al. Single-atom Fe with $\mathrm{Fe}_{1} \mathrm{~N}_{3}$ structure showing superior performances for both hydrogenation and transfer hydrogenation of nitrobenzene. Sci. China Mater. 64, 642-650 (2021).

42. Yang, F. et al. Atomically dispersed $\mathrm{Ni}$ as the active site towards selective hydrogenation of nitroarenes. Green. Chem. 21, 704-711 (2019).

43. Wang, X. \& Li, Y. Chemoselective hydrogenation of functionalized nitroarenes using MOF-derived Co-based catalysts. J. Mol. Catal. A: Chem. 420, 56-65 (2016)

44. Kuai, L. et al. Titania supported synergistic palladium single atoms and nanoparticles for room temperature ketone and aldehydes hydrogenation. Nat. Commun. 11, 48 (2020).

45. Liu, P. et al. Photochemical route for synthesizing atomically dispersed palladium catalysts. Science 352, 797-801 (2016).

46. Bai, L. et al. Explaining the size dependence in platinum-nanoparticle-catalyzed hydrogenation reactions. Angew. Chem. Int. Ed. 55, 15656-15661 (2016).

47. Qin, R. et al. Alkali ions secure hydrides for catalytic hydrogenation. Nat. Catal. 3, 703-709 (2020).

48. Liu, W. et al. A durable nickel single-atom catalyst for hydrogenation reactions and cellulose valorization under harsh conditions. Angew. Chem. Int Ed. 57, 7071-7075 (2018).

49. Merte, L. R. et al. Water-mediated proton hopping on an iron oxide surface Science 336, 889-893 (2012)

50. Ravel, B. \& Newville, M. ATHENA, ARTEMIS, HEPHAESTUS: data analysis for X-ray absorption spectroscopy using IFEFFIT. J. Synchrotron Radiat. 12 537-541 (2005)

51. Kresse, G. \& Joubert, D. From ultrasoft pseudopotentials to the projector augmented-wave method. Phys. Rev. B 59, 1758-1775 (1999).

52. Kresse, G. \& Furthmuller, J. Efficiency of ab-initio total energy calculations for metals and semiconductors using a plane-wave basis set. Comp. Mater. Sci. 6, 15-50 (1996).

53. Kresse, G. \& Furthmuller, J. Efficient iterative schemes for ab initio totalenergy calculations using a plane-wave basis set. Phys. Rev. B 54, 11169-11186 (1996).

54. Grimme, S., Antony, J., Ehrlich, S. \& Krieg, H. A consistent and accurate ab initio parametrization of density functional dispersion correction (DFT-D) for the 94 elements H-Pu. J. Chem. Phys. 132, 154104 (2010).

55. Blochl, P. E. Projector augmented-wave method. Phys. Rev. B 50, 17953-17979 (1994). 
56. Perdew, J. P., Burke, K. \& Ernzerhof, M. Generalized gradient approximation made simple. Phys. Rev. Lett. 77, 3865-3868 (1996).

57. Henkelman, G., Uberuaga, B. P. \& Jonsson, H. A climbing image nudged elastic band method for finding saddle points and minimum energy paths. $J$. Chem. Phys. 113, 9901-9904 (2000).

58. Henkelman, G. \& Jonsson, H. Improved tangent estimate in the nudged elastic band method for finding minimum energy paths and saddle points. J. Chem. Phys. 113, 9978-9985 (2000).

\section{Acknowledgements}

We thank the National Key R\&D Program of China (Grant No. 2018YFA0703503 and 2018YFA0208504, C.C. and W.S.), the National Natural Science Foundation of China (NSFC 21932006, W.S.), the Youth Innovation Promotion Association of CAS (2017049, C.C.), Beijing Outstanding Young Scientist Program (BJJWZYJH01201914430039, W.Z.) and National Science Basic Research Program of Shaanxi (No. S2020-JC-WT-0001, X.Y.) for financial support. We thank the beamline 1W1B station in Beijing Synchrotron Radiation Facility (BSRF) and Dr. Lirong Zheng for help in XAFS characterization.

\section{Author contributions}

H.J., C.C., and W.S. were responsible for most of the investigations, methodology development, data collection/analysis, and writing the original manuscript. P.L. assisted with the experiments analysis. X.Y. conducted the DFT calculations. P.C. helped to analyze the XAFS results. J.S. and W.Z. helped to conduct the atomic-resolution EELS. C.C. and W.S. were responsible for the funding and resources acquisition, supervising the project, revising, and editing the manuscript.

\section{Competing interests}

The authors declare no competing interests.

\section{Additional information}

Supplementary information The online version contains supplementary material available at https://doi.org/10.1038/s41467-022-28367-9.

Correspondence and requests for materials should be addressed to Xiaohu Yu or Changyan Cao.

Peer review information Nature Communications thanks Chun Zhang, Jianglan Shui and the other, anonymous, reviewers for their contribution to the peer review of this work. Peer reviewer reports are available.

Reprints and permission information is available at http://www.nature.com/reprints

Publisher's note Springer Nature remains neutral with regard to jurisdictional claims in published maps and institutional affiliations.

\section{(c) (i)}

Open Access This article is licensed under a Creative Commons Attribution 4.0 International License, which permits use, sharing, adaptation, distribution and reproduction in any medium or format, as long as you give appropriate credit to the original author(s) and the source, provide a link to the Creative Commons license, and indicate if changes were made. The images or other third party material in this article are included in the article's Creative Commons license, unless indicated otherwise in a credit line to the material. If material is not included in the article's Creative Commons license and your intended use is not permitted by statutory regulation or exceeds the permitted use, you will need to obtain permission directly from the copyright holder. To view a copy of this license, visit http://creativecommons.org/ licenses/by/4.0/.

(C) The Author(s) 2022 